\title{
Large-scale circulation classification and its links to observed precipitation in the eastern and central Tibetan Plateau
}

\author{
Wenbin Liu ${ }^{1}$ Lei Wang ${ }^{2,3} \cdot$ Deliang Chen $^{4} \cdot \mathrm{Kai} \mathrm{Tu}^{5} \cdot$ Chengqing Ruan $^{6} \cdot$ \\ Zengyun $\mathrm{Hu}^{7}$
}

Received: 29 January 2015 / Accepted: 24 July 2015 / Published online: 5 August 2015

(C) Springer-Verlag Berlin Heidelberg 2015

\begin{abstract}
The relationship between the large-scale circulation dynamics and regional precipitation regime in the Tibetan Plateau (TP) has so far not been well understood. In this study, we classify the circulation types using the selforganizing maps based on the daily field of $500 \mathrm{hPa}$ geopotential height and link them to the precipitation climatology in the eastern and central TP. By virtue of an objective determining method, 18 circulation types are quantified. The results show that the large amount of precipitation in summer is closely related to the circulation types in which the enhanced and northward shifted subtropical high (SH) over the northwest Pacific and the obvious cyclconic circulation anomaly over the Bay of Bengal are helpful for the Indian summer monsoon and East Asian summer monsoon
\end{abstract}

Wenbin Liu

liuwb@itpcas.ac.cn

1 Key Laboratory of Water Cycle and Related Land Surface Processes, Institute of Geographic Sciences and Natural Resources Research, Chinese Academy of Sciences, Beijing, China

2 Key Laboratory of Tibetan Environment Changes and Land Surface Processes, Institute of Tibetan Plateau Research, Chinese Academy of Sciences, Beijing, China

3 CAS Center for Excellence in Tibetan Plateau Earth Sciences, Beijing, China

4 Department of Earth Sciences, University of Gothenburg, Gothenburg, Sweden

5 RCE-TEA, Institute of Atmospheric Physics, Chinese Academy of Sciences, Beijing, China

6 LASG, Institute of Atmospheric Physics, Chinese Academy of Sciences, Beijing, China

7 State Key Laboratory of Desert and Oasis Ecology, Xinjiang Institute of Ecology and Geography, Chinese Academy of Sciences, Urumqi, China to take abundant low-latitude moisture to the eastern and southern TP. On the contrary, the dry winter in the central and eastern Tibet corresponds to the circulation types with divergence over the central and eastern TP and the water vapor transportations of East Asian winter monsoon and mid-latitude westerly are very weak. Some circulation types are associated with some well-known circulation patterns/monsoons influencing the TP (e.g. East Atlantic Pattern, El Niño Southern Oscillation, Indian Summer Monsoon and the mid-latitude westerly), and exhibit an overall good potential for explaining the variability of regional seasonal precipitation. Moreover, the climate shift signals in the late 1970s over the eastern Pacific/North Pacific Oceans could also be reflected by both the variability of some circulation types and their correspondingly composite precipitations. This study extends our understandings for the large-scale atmospheric dynamics and their linkages with regional precipitation and is beneficial for the climate change projection and related adaptation activities in the highest and largest plateau in the world.

Keywords Self-organizing maps $\cdot$ Circulation classification - Precipitation - Tibetan Plateau - ENSO . Climate change

\section{Introduction}

Knowledge about precipitation and its variability is undoubtedly important for understanding the regional water cycles, and thus for water resource management, drought and flood forecasting as well as agriculture production under the changing climate (IPCC 2013). It is especially crucial for the highest plateau in the world, the Tibetan Plateau (TP), which is subjected to strong interactions among 
different components of the Earth system (atmosphere, cryosphere, hydrosphere and biosphere) and is one of the most vulnerable regions under global warming background (Duan and $\mathrm{Wu} 2006$ ). It is also the headwater area of some major Asian rivers, including Indus river, Ganga-Brahmaputra river, Yangtze river, Yellow river and Mekong river, which provides a large portion of water resources for the economical development in China and the surrounding countries (Immerzeel et al. 2010).

During the past three decades (1984-2006), observed precipitation exhibited significant enhancement in the central TP while decreasing along the TP periphery (Yang et al. 2011, 2014). Moreover, precipitation extremes depicted by most of the precipitation indices show increasing trends in the southern and northern regions but reveal declining trends in the central TP (You et al. 2008). Correspondingly, some distinct changes are induced for glaciers, lake levels and river discharge in the plateau (Immerzeel et al. 2010; Yao et al. 2012; Lei et al. 2014). However, the reasons behind the precipitation variability/change in the TP are still to a large extent unclear, which call for further studies.

Large-scale atmospheric circulations have major influences on local precipitation variations at both shorter weather time scales and longer climate time scales, and the investigations for their linkages could thus be beneficial for improving our understandings on regional precipitation regime and for the purpose of empirical precipitation forecasting/downscaling (Tveito 2010). On the climate time scale, the TP climate is under the combined and competitive influences of South Asian and East Asian Monsoons and of the mid-latitude westerlies (Webster et al. 1998; Schiemann and Schaer 2009). In the summer monsoon season, the southeastern TP is a moisture sink with water vapor transports from the Indian Ocean and the Bay of Bengal (Feng and Zhou 2012). Moreover, the water vapor is also contributed strongly to the passing of the synoptic trough but impeded by the cyclonic circulation over the Indian Ocean (Sugimoto et al. 2008). The precipitation in the TP is closely related to the atmospheric circulation anomalies in the North-Atlantic/European sector (Liu and Yin 2001; Bothe et al. 2010, 2012), and that in the southeast TP is also influenced by the Atlantic sea surface temperature (SST) anomalies through the Rossby wave responses (Gao et al. 2013). Nevertheless, the explanations for the variability of TP precipitation via just a few circulation types, for example, some predefined circulation indices, are still not sufficient. A comprehensive investigation by considering all types of large-scale atmospheric circulation is expected but has currently been less studied in the TP.

Circulation classification is one of the better and wellestablished tools in synoptic climatology for exploring the dynamics of large-scale circulations and their linkages with the variability of near-surface climate (Chen 2000; Yarnal et al. 2001; Belleflamme et al. 2015). So far, there are a large number of approaches, as summarized in the framework of the Earth System Sciences and Environmental Management COST Action 733 in Europe (Philipp et al. 2014), which could be grouped into subjective methods, hybrid methods and the objective methods (Huth et al. 2008). Over the course of time the original subjective methods, such as those applied by Lamb (1950), define the synoptic types based on the visual inspection of weather maps, which are usually effective and allow physical interpretation of the climate variability but extremely labor intensive (Hewitson and Crane 2002). The hybrid method, such as the widely used Grosswetterlagen (James 2007), involves some manual initial identification of different synoptic types in the classification. In recent years, many objective methods (e.g. Artificial Neural Networks, ANN) which essentially employ quantitative algorithms were developed and widely applied with the development of the computer technique (Huth et al. 2008; Sheridan and Lee 2011). The self-organizing map (SOM) technique is an efficient neural network method in objective classification, which groups a potentially large, multivariate dataset into a two-dimensional array of cluster types that 'self-organized' using the unsupervised iterative training procedure (Kohonen 2001). An outstanding advantage of the SOM over other traditional methods is that the Kohonen technique treats the synoptic categories as a continuum and presents both the basic and transitional patterns in an array, which make the patterns classified readily be understood and visualized (Rousi et al. 2015). During the past several years, the SOM has become increasingly popular in atmospheric and oceanic sciences in Europe, Unite States, South Africa and Australia (Cavazos 2000; Hewitson and Crane 2002; Cassano et al. 2006; Johnson et al. 2008; Verdon-Kidd and Kiem, 2009; Liu and Weisberg 2011; Johnson 2013; Lennard and Hegerl 2014). However, very few related studies have been found so far in China, especially in the TP.

In this study, daily large-scale circulation patterns influencing the precipitation regime in the eastern and central TP are firstly characterized through the use of SOMs technique. Moreover, the potential implications of circulation types for explaining the impacts of archetypical patterns on the variability and change of the TP precipitation are also attempted. The paper is organized as follows: the next Section explains the data and method adopted in this study including a brief description of the study regions. Section 3 presents the main results, which include the SOM cluster patterns and their linkages with well-recognized teleconnection patterns, monsoons and local precipitation in the TP, and related discussions. Additionally, a summary and some conclusions are presented in Sect. 4. 


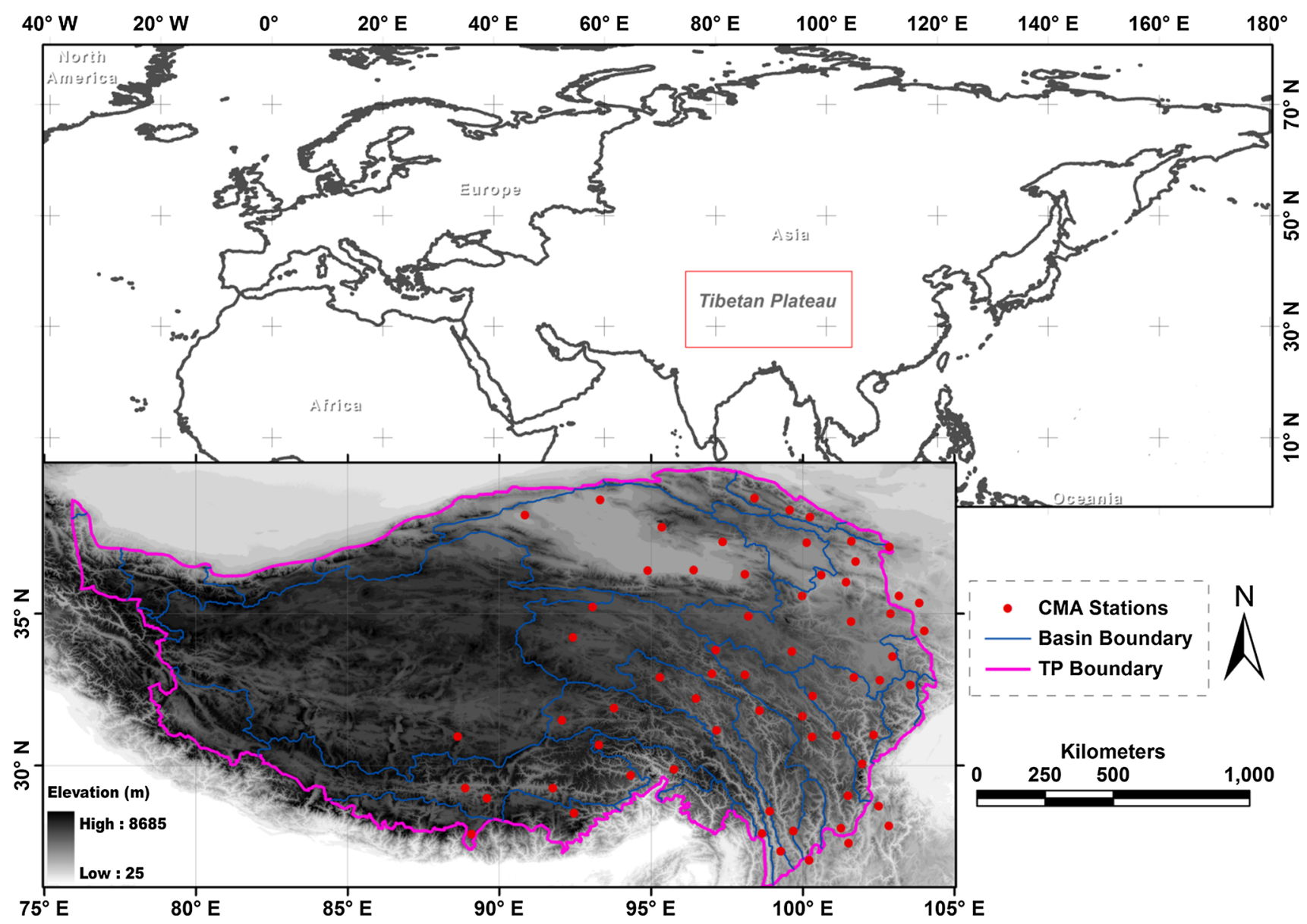

Fig. 1 Location of the Tibetan Plateau showing the domain used to classify the circulation types (upper panel) and the meteorological stations in the central and eastern parts (lower panel) used in this study. The shading in the lower-panel shows the elevation of Tibetan Plateau

\section{Data and methodology}

\subsection{Study regions}

There are two specific regions involved in this study (Fig. 1). The small one is shown limited to the plateau extending over $25^{\circ}-40^{\circ} \mathrm{N}$ and $75^{\circ}-105^{\circ} \mathrm{E}$, with an area of about $2.5 \times 10^{6} \mathrm{~km}^{2}$. Due to lack of precipitation observations in the western region only the eastern and central TP were included for analyzing the relationships between the atmospheric circulation categories and local precipitation. Another region is a broader area $\left(0^{\circ}-80^{\circ} \mathrm{N}\right.$ and $40^{\circ} \mathrm{W}-180^{\circ} \mathrm{E}$ ) over Europe, Asia and parts of Africa chosen for the large-scale circulation classification, which covers the centers of actions for almost all important circulation systems (e.g. the mid-latitude westerlies, East Asian Monsoon, Indian summer Monsoon, subtropical highs (SHs), Mongolian High and the Polar vertex) that affect the TP climate (Webster et al. 1998; Schiemann and Schaer 2009).

\subsection{Data}

The observed daily precipitation records used in this study are provided by the China Meteorological Data Sharing Service System (http://cdc.cma.gov.cn). There are 85 stations (mainly located in the central and eastern regions) in the data sparse TP, but their operations were started in different years (most are from January 1 in 1961) and there are missing values at some stations in the early decades. After considering the data consistency and removing the stations with missing data, 64 stations (among them 12 stations have altitudes above $4000 \mathrm{~m}$ ) with complete daily precipitation records (no missing values) during the 19612010 are applied (Fig. 1). Additionally, the daily geopotential heights at $500 \mathrm{hPa}$ isobaric level (GH500) with the spatial resolution $2.5^{\circ}$ latitude $\times 2.5^{\circ}$ longitude used for circulation typing are obtained from the National Centers for Environmental Prediction/National Center for Atmospheric Research (NCEP/NCAR, http://www.esrl.noaa. gov/psd/data/grided/data.ncep.reanalysis.html) reanalysis 
Table 1 Descriptions of major teleconnection patterns and monsoon indices used in this study

\begin{tabular}{|c|c|c|c|}
\hline Indices & Acronym & Source organization and associated website & References \\
\hline North Atlantic Oscillation & NAO & & Barnston and Livezey (1987) \\
\hline East Atlantic pattern & EA & & \\
\hline East Atlantic/Western Russia pattern & EA/WR & & \\
\hline Scandinavia pattern & SCA & $\begin{array}{l}\text { NOAA climate prediction center, www.cpc.ncep.noaa.gov/data/ } \\
\text { teledoc/telecontents.shtml }\end{array}$ & \\
\hline Pacific/North American pattern & PNA & & \\
\hline Polar/Eurasia pattern & POL & & \\
\hline East Pacific/North Pacific pattern & EA/NP & & \\
\hline El Niño-Southern Oscillation index & ENSO & $\begin{array}{l}\text { Climate analysis section of climate and global dynamics in } \\
\text { NCAR. www.cgd.ucar.edu/cas/catalog/climind/Nino_3_3.4_ } \\
\text { indices.html }\end{array}$ & Trenberth (1997) \\
\hline Pacific Decadal Oscillation & PDO & $\begin{array}{l}\text { Joint Institute for the study of the Atmosphere and Ocean. http:// } \\
\text { jisao.wathington.edu/pdo/ }\end{array}$ & Chan and Zhou (2005) \\
\hline Zonal Index & ZI & $\begin{array}{l}\text { Dr. Jianping Li’s homepage in College of Global Change and } \\
\text { Earth System }\end{array}$ & Li and Zeng (2003b) \\
\hline East Asian Summer Monsoon index & EASMI & $\begin{array}{l}\text { Sciences in Beijing Normal University. ljp.gcess.cn/dct/ } \\
\text { page/ } 65544\end{array}$ & Li and Wang (2003a) \\
\hline Indian summer monsoon index & ISMI & $\begin{array}{l}\text { International Pacific Research Center in the School of Ocean } \\
\text { and Earth Science and Technology at the University of Hawaii. } \\
\text { http://apdrc.soest.hawaii.edu/projects/monsson/seasonal- } \\
\text { monidx.html }\end{array}$ & Wang et al. (2001) \\
\hline
\end{tabular}

dataset (Kalnay et al. 1996). The average elevation in the TP exceeds $4000 \mathrm{~m}$ ASL (above sea level) and the subsurface parameters, such as sea level pressure are subject to errors of extrapolation. Therefore, the GH500 are chosen as a compromise between sea level pressure and $200 \mathrm{hPa}$ geopotential heights so that the patterns are near the surface of the plateau. It is extracted for the region selected (the bigger domain in Fig. 1) and for the same period as the observed precipitation. Moreover, to consider the dependence of grid-point density on latitude, the GH500 fields are first weighted by the square root of cosine (latitude) in the subsequent analysis because the GH500 fields are on a sphere (Johnson and Feldstein 2010).

To identify the linkages between the classified circulation types and major teleconnection patterns/monsoons influencing the plateau, 12 indices were adopted in this study. They include seven northern hemisphere teleconnection patterns (North Atlantic Oscillation, East Atlantic pattern, East Atlantic/Western Russia, Scandinavia pattern (SCA), Pacific/ North American pattern, Polar/Eurasia Pattern and East Pacific/North Pacific pattern), which are recurring and persistent large-scale patterns of pressure/circulation anomalies spans vast geographical areas, and influence temperature, precipitation and storm tracks over wide regions. Moreover, the El Niño-Southern Oscillation (ENSO) index, Pacific Decadal Oscillation (PDO) index as well as three monsoon indices (Zonal index, East Asian Summer Monsoon Index and Indian Summer Monsoon Index), which were proved the predominant monsoons affecting the TP climate (Trenberth 1997; Chan and Zhou 2005; Yao et al. 2012), are also used. For more information (for example, the source organization and associated website) please refer to Table 1.

\section{Methods}

The artificial neural network system of SOM was firstly detailed in Kohonen (1995) and was introduced to the atmospheric sciences by Hewitson and Crane (2002). A SOM is essentially a topology-preserving nonlinear mapping of numerous vectors in the original data space onto a low-dimensional map (usually a two-dimensional regular lattice) of archetypal nodes based on competitive learning (Kohonen 2001). During the unsupervised learning processes of SOM, no priori assumption regarding the final clusters is required. The final master SOMs learn from the input data while the types become characteristic of the input data through being "trained" by them (Cassano et al. 2006; Rousi et al. 2015). For more details about the theory and its atmospheric implications, please refer to Hewitson and Crane (2002), Gutiérrez et al. (2005) and Liu et al. (2006). Once the master SOMs are confirmed, the amplitude series corresponding to each circulation type can be calculated (Johnson and Feldstein 2010).

The SOM toolbox written in Matlab (version 2.0) is used in this paper for categorizing patterns in original 
daily GH500 field, which can be downloaded freely from the Helsinki University of Technology in Finland (http:// www.cis.hut.fi/projects/somtoolbox/). In this toolbox, some decisions have to be made by researchers. For example, the batch training is chosen in this study due to its higher computational efficiency when compared to the sequential training (Vesanto et al. 2000). Additionally, the "ep" type neighborhood function and the "rectangle" topology are adopted after a certain number of sensitivity experiments for balancing the computational efficiency and the best description of the representative patterns in the input data. Another important parameter is the size of the SOM map, which is sensitive to the output of the self organizing neural network but is usually specified subjectively. However, it could be objectively determined through examining the saturation in the reduction of two criteria for evaluating the fitting of the neural map to the original data (the quantization error: q-error) and the topology preservation in the SOM classification (the topological error: t-error), respectively (Rousi et al. 2015). The q-error and t-error could be calculated as:

q-error $=\frac{1}{\mathrm{~N}} \sum_{i=1}^{N}\left\|\overrightarrow{\mathrm{x}_{1}}-\mathrm{m}_{\overrightarrow{\mathrm{x}_{1}}}\right\|$

t-error $=\frac{1}{\mathrm{~N}} \sum_{i=1}^{N} \mathrm{u}\left(\overrightarrow{\mathrm{x}_{1}}\right)$

where, $\mathrm{m}_{\overrightarrow{\mathrm{x}_{1}}}$ is the best matching prototype of the corresponding data-vector $\overrightarrow{\mathrm{x}_{1}}$ and $\mathrm{N}$ is the number of datavectors. If $\overrightarrow{x_{1}}$ data vector's first and second Best Matching Units (BMUs) are adjacent, $\mathrm{u}\left(\overrightarrow{\mathrm{x}}_{1}\right)$ equals 1 and 0 otherwise. A small q-error represents a good clustering. The lower the t-error, the better the SOM preserves the topology. Rousi et al. (2015) selected the optimal SOM size by detecting the abrupt change of t-error using the Mann-Kendall test. Similarly, in this study, the SOM grid $(\mathrm{i} \times \mathrm{j})$ was evaluated for different sizes ( $\mathrm{i}, \mathrm{j}$ increase gradually from 3 to 10 ) and thus resulting in 64 combinations for the input dataset (Table 2). To avoid multiple change points being examined, Pettitt non-parametric test (Pettitt 1979) coupled with student $t$-test is used for detecting the likely abrupt change in the series of the sum of q-error and t-error corresponding to the created SOM maps. For a data series $x(n)$, the Pettitt statistics $k(\tau)$ could be computed on the separated two subsamples before and after the potential change point $\tau$,

$k(\tau)=\sum_{i=1}^{\tau} \sum_{j=\tau+1}^{n} \operatorname{sgn}\left(x_{j}-x_{i}\right)$

here, the sign function (sgn) is defined as:

$\operatorname{sgn}\left(x_{j}-x_{i}\right)=\left\{\begin{array}{c}1 \quad \text { if } x_{j}>x_{i} \\ 0 \quad \text { if } x_{j}=x_{i} \\ -1 \quad \text { if } x_{j}<x_{i}\end{array}\right.$ when the absolute value of $k(\tau)$ reaches the maximum $K$, the abrupt change most likely takes place. Thus, $K, T$ and the significance probability for rejecting the no change assumption could be expressed as:

$T=\arg \max _{1 \leq \tau \leq n}(|k(\tau)|)$

$K=\max _{1 \leq \tau \leq n}(|k(\tau)|)$

$P \approx 2 \exp \left(\frac{-6 k^{2}}{n^{3}-n^{2}}\right)$

The Pettitt test usually reports the most possible change point in a time series. To further examine if the sub-series before and after the change point is substantially different from each other, the student t-test is also used in this study. This method is also applied to detect the abrupt change in other variables such as the annual frequencies of circulation types and their corresponding composite precipitation. The Pearson correlation coefficient is used to evaluate the linear correlations between two variables and the 0.05 significance level is adopted to test whether the correlations/ trends are statistically significant. Moreover, the stepwise linear regression (SLR) is also applied in this paper to test the explaining capacity of the classified circulation types to regional precipitation. The frequency and amplitude series of all seasonal types are first taken as the potential predictors for the seasonal precipitation in the central and eastern TP, and the reasonable predictors with relatively higher explaining capacity are selected by virtue of a backward elimination algorithm. Finally, four seasonal SLR models are built to reconstruct the seasonal precipitation using the reasonable circulation types.

\section{Results and discussion}

\subsection{Classified circulation types and their intra-annual distributions}

At first we objectively examine the number of circulation patterns which appear in the selected region using the Pettitt test coupled with a two-sample student t-test. Based on this method, a significant abrupt change point (the 25th point in the upper panel of Fig. 2, which corresponds to a $3 \times 6$ SOM size in Table 2) is detected in the series of the sum of q-error and t-error, which indicates 18 distinctive circulation patterns with $3 \times 6$ SOM topology can satisfactorily describe the variations of the synoptic situations in TP. Moreover, the resultant Sammon map (Sammon 1969) is also provided in the lower panel of Fig. 2, which shows 
Table 2 Q-error and t-error values for all SOM size combinations tested

\begin{tabular}{|c|c|c|c|c|c|c|c|}
\hline No. & SOM size & q-error & t-error & No. & SOM size & q-error & t-error \\
\hline 1 & $3 \times 3$ & 39.34 & 0.02 & 33 & $3 \times 7$ & 38.24 & 0.18 \\
\hline 2 & $4 \times 3$ & 39.87 & 0.14 & 34 & $4 \times 7$ & 35.97 & 0.10 \\
\hline 3 & $5 \times 3$ & 39.44 & 0.33 & 35 & $5 \times 7$ & 36.29 & 0.14 \\
\hline 4 & $6 \times 3$ & 38.85 & 0.17 & 36 & $6 \times 7$ & 36.14 & 0.17 \\
\hline 5 & $7 \times 3$ & 38.68 & 0.38 & 37 & $7 \times 7$ & 35.23 & 0.13 \\
\hline 6 & $8 \times 3$ & 37.03 & 0.28 & 38 & $8 \times 7$ & 35.70 & 0.08 \\
\hline 7 & $9 \times 3$ & 37.34 & 0.14 & 39 & $9 \times 7$ & 36.67 & 0.14 \\
\hline 8 & $10 \times 3$ & 37.07 & 0.16 & 40 & $10 \times 7$ & 34.90 & 0.11 \\
\hline 9 & $3 \times 4$ & 38.35 & 0.04 & 41 & $3 \times 8$ & 36.66 & 0.37 \\
\hline 10 & $4 \times 4$ & 36.92 & 0.13 & 42 & $4 \times 8$ & 36.04 & 0.20 \\
\hline 11 & $5 \times 4$ & 37.72 & 0.10 & 43 & $5 \times 8$ & 35.33 & 0.10 \\
\hline 12 & $6 \times 4$ & 37.73 & 0.05 & 44 & $6 \times 8$ & 36.28 & 0.17 \\
\hline 13 & $7 \times 4$ & 37.00 & 0.10 & 45 & $7 \times 8$ & 35.15 & 0.17 \\
\hline 14 & $8 \times 4$ & 37.04 & 0.11 & 46 & $8 \times 8$ & 34.81 & 0.12 \\
\hline 15 & $9 \times 4$ & 36.76 & 0.29 & 47 & $9 \times 8$ & 36.39 & 0.07 \\
\hline 16 & $10 \times 4$ & 36.32 & 0.20 & 48 & $10 \times 8$ & 36.27 & 0.07 \\
\hline 17 & $3 \times 5$ & 37.85 & 0.07 & 49 & $3 \times 9$ & 37.21 & 0.18 \\
\hline 18 & $4 \times 5$ & 36.53 & 0.06 & 50 & $4 \times 9$ & 36.91 & 0.09 \\
\hline 19 & $5 \times 5$ & 36.60 & 0.11 & 51 & $5 \times 9$ & 36.47 & 0.11 \\
\hline 20 & $6 \times 5$ & 37.33 & 0.39 & 52 & $6 \times 9$ & 36.04 & 0.25 \\
\hline 21 & $7 \times 5$ & 36.22 & 0.27 & 53 & $7 \times 9$ & 35.20 & 0.14 \\
\hline 22 & $8 \times 5$ & 36.60 & 0.06 & 54 & $8 \times 9$ & 36.31 & 0.10 \\
\hline 23 & $9 \times 5$ & 36.30 & 0.14 & 55 & $9 \times 9$ & 35.31 & 0.07 \\
\hline 24 & $10 \times 5$ & 36.23 & 0.02 & 56 & $10 \times 9$ & 34.86 & 0.16 \\
\hline 25 & $3 \times 6$ & 38.51 & 0.09 & 57 & $3 \times 10$ & 37.79 & 0.06 \\
\hline 26 & $4 \times 6$ & 36.50 & 0.17 & 58 & $4 \times 10$ & 37.30 & 0.05 \\
\hline 27 & $5 \times 6$ & 36.54 & 0.12 & 59 & $5 \times 10$ & 35.67 & 0.15 \\
\hline 28 & $6 \times 6$ & 36.14 & 0.11 & 60 & $6 \times 10$ & 36.64 & 0.18 \\
\hline 29 & $7 \times 6$ & 36.18 & 0.20 & 61 & $7 \times 10$ & 36.02 & 0.04 \\
\hline 30 & $8 \times 6$ & 36.05 & 0.25 & 62 & $8 \times 10$ & 35.96 & 0.11 \\
\hline 31 & $9 \times 6$ & 36.88 & 0.06 & 63 & $9 \times 10$ & 34.47 & 0.14 \\
\hline 32 & $10 \times 6$ & 35.81 & 0.14 & 64 & $10 \times 10$ & 35.66 & 0.09 \\
\hline
\end{tabular}

Numbers with bold font show that the $3 \times 6$ SOM nodes were objectively selected in this study, by virtue of the abrupt point detection using the Pettitt test shown in Fig. 2 a reasonable topology properties of the master SOMs classified with the most similar patterns neighbor and the most dissimilar patterns far away from each other(Johnson et al. 2008).

Overall, there appears to be two distinct groups and some transitional patterns in Fig. 3. For example, types A1, A2, B5 are dominating patterns during wintertime while types B4, C4 and C5 are primarily summertime patterns. Specifically, type A1occurs primarily during November to April (Fig. 4) with a deepest and steady Eastern Asia Trough (EAT) along $140^{\circ} \mathrm{E}$ and a shallow Eastern Europe Trough (EET) around $40^{\circ} \mathrm{E}$ (Fig. 3). Type A2 and type B5, which have a very broad and deep EAT as well but the location shift to $150^{\circ} \mathrm{E}$, appear mainly during late winter (January to March) and occasionally in November. Moreover, the
EET varies unobtrusively but a minor perturbation appears over the Caspian Sea. Type B6 and type C6, which usually exist in winter (December to February), early spring (March to April) and late autumn (October to November), are very similar to type A2 but the EAT and EET become broader and shallower in type B6 and the EAT looks much shallower in type C6. Additionally, the westerly perturbations over the Middle East in type B6 have not developed. Comparing to type A2, type A3 has a relatively weaker EAT and a shallower EET, which often exists during the seasonal transitions between autumn and winter and between winter and spring. SHs in the west Pacific in types A1, A2, A3, B5 and B6 are relatively weaker with their ridge lines shift southward (over the Philippines) and there are anticyclonic circulation anomalies over the Bay of Bengal. Type 
A4, appearing mainly in March, April, November, December and January (Fig. 4), is quite similar to type A3 but the EAT looks stronger and the westerly is more stable.

Type A5 mainly occurs in April, May, October and November (Fig. 4), in which the EAT nearly disappears and the mid-latitude westerly is dominant over high latitudes. Moreover, the trough over the Bay of Bengal in type A5 is very clear but not strong and the troughs over
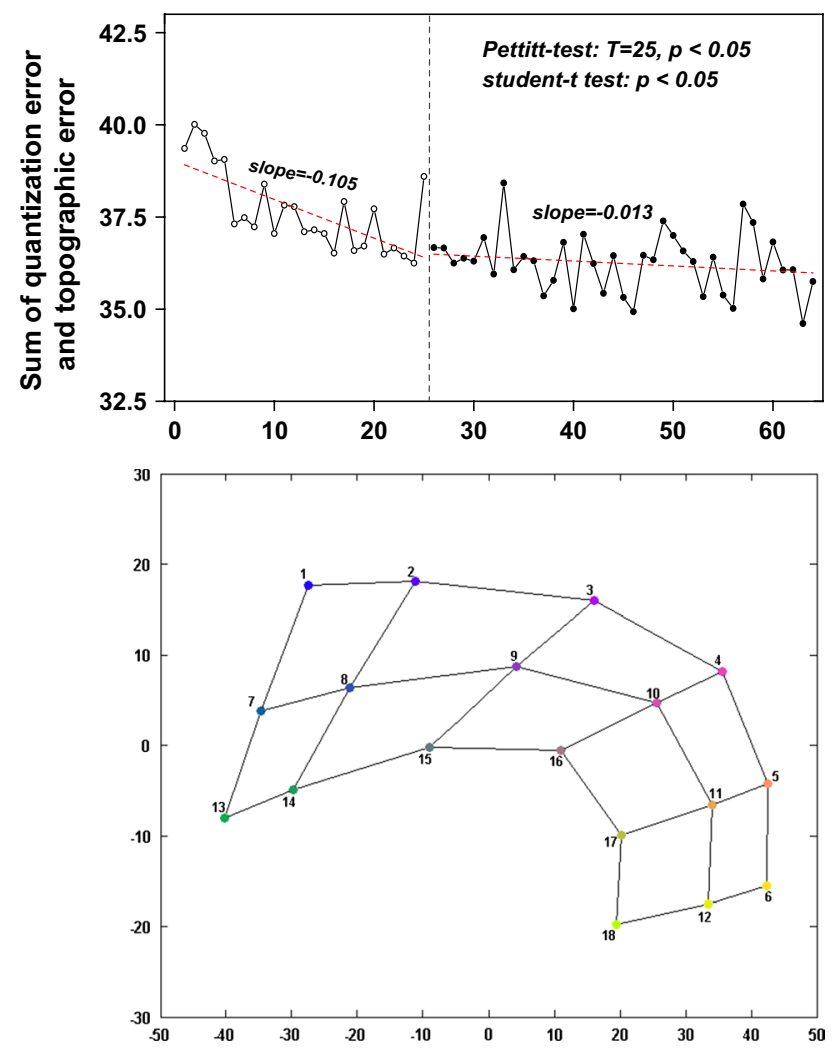

Fig. 2 The upper panel shows Pettitt-test and student's t-test on different SOM sizes' errors for detecting the optimal SOM size, whereas the lower panel shows the Sammon map for the selected $3 \times 6$ nodes which the positions of the SOM patterns the Mediterranean are significant. Type A6 and type B1 are fairly close to type A5, but with relatively stronger trough in Bangladesh Bay and a weaker EAT, which are both transitional patterns mainly appear in late spring and early autumn. Similarly, types B2, C2 and C3 are also primarily emerge in mid-late spring (April to June) and early-mid autumn (September to October). However, the SHs over the northwest Pacific and perturbations are relatively stronger in type B2, the EAT gets stronger in type $\mathrm{C} 3$ and the geopotential height appears lower as a whole in type $\mathrm{C} 2$. Similar to type B1, the mid-latitude westerly is dominant and the isolines are more compact in type $\mathrm{C}$, which always appear in spring (March to May) and late autumn (October to December). Additionally, there are two prominent SHs in type B3 with one above western Pacific and another above Asia and northern Africa. Type B4 is similar to type B3, but has a noticeable trough over the Aleutian Islands. The GH500 fields over the Bay of Bengal are relatively lower in type B4 and type B5, which indicate obvious cyclconic circulation anomalies. Moreover, the position of $\mathrm{SH}$ ridge lines in the west Pacific is normal by north (over the Taiwan Island). The EAT moves to the Aleutian Island in type $\mathrm{C} 4$ and a shallow trough appears over the eastern Mediterranean, but the SHs have not fully developed yet. In type $\mathrm{C} 5$, the $\mathrm{SH}$ over the northern Africa appears relatively stronger and a low pressure center (probably tropical cyclones) exists over the Bangladesh Bay. Types B3, B4, C4 and C5 are all typical summertime (June to September) types with distinct strengthening in the SHs over the northwest Pacific.

\subsection{Composite precipitations corresponding to each circulation type and their intra-annual distributions}

We interpolated the station-based composite precipitations corresponding to each circulation type to contiguous
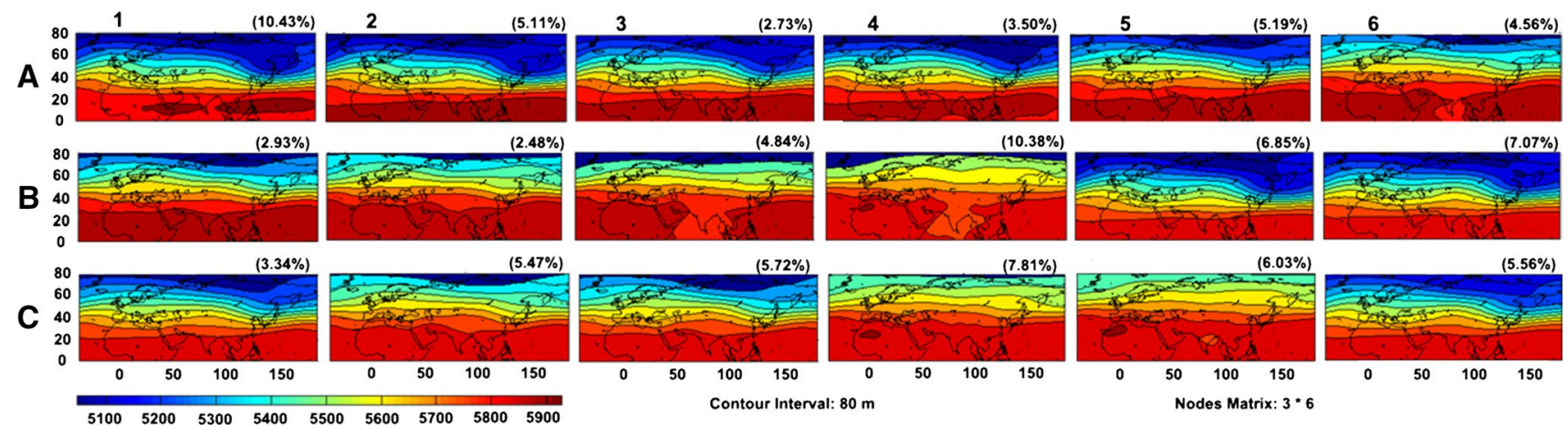

Fig. 3 Master SOM $(3 \times 6)$ of $500 \mathrm{hPa}$ geopotential heights states for the period 1961-2010 


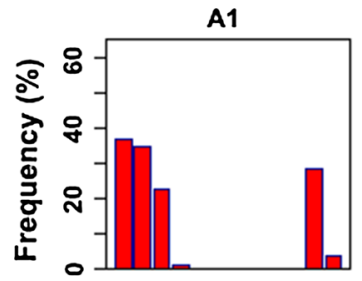

B1

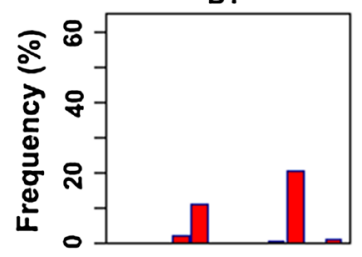

C1

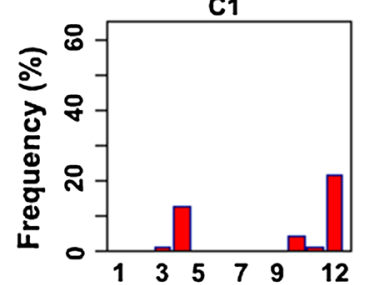

A2

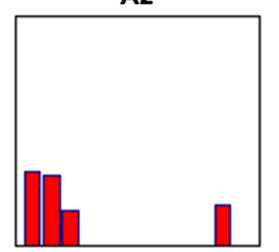

B2

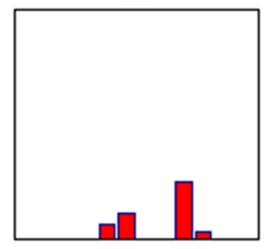

C2

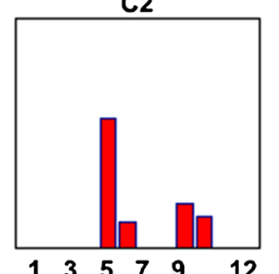

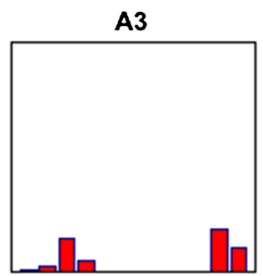

B3

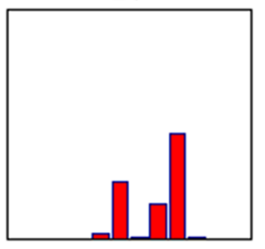

C3

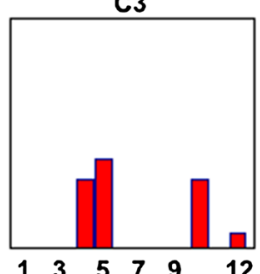

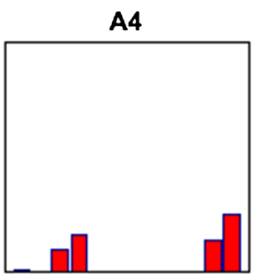

B4

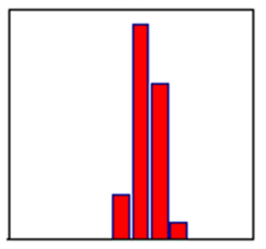

C4

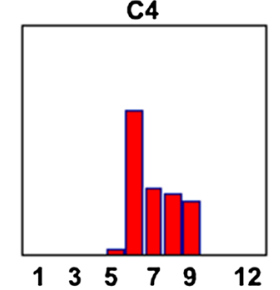

Months

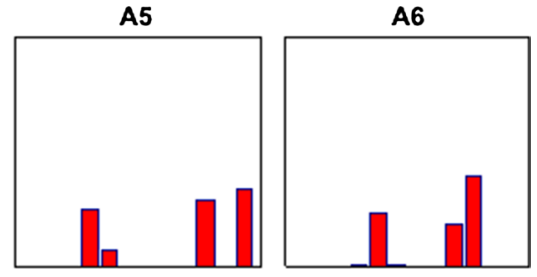

B5

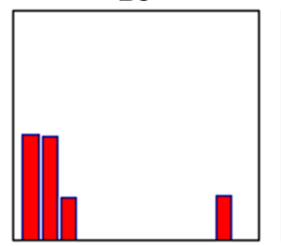

C5

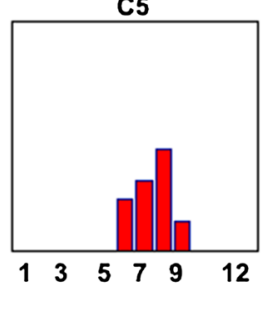

B6

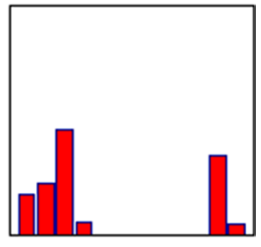

c6

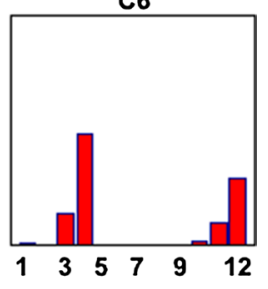

Fig. 4 Monthly frequency distribution for each of 18 synoptic circulation types
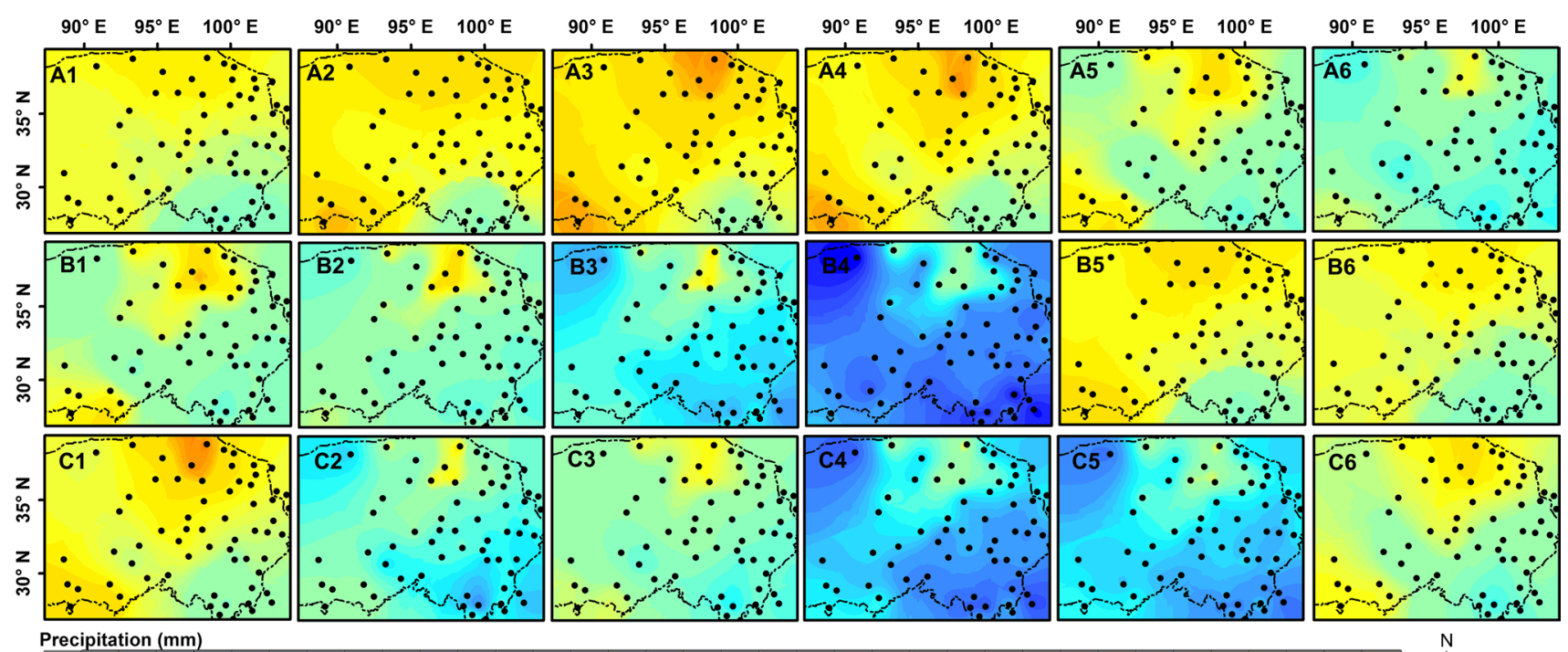

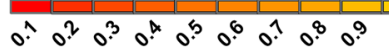

Fig. 5 Spatial patterns of the composite precipitation distribution corresponding to each of the 18 circulation types (mm/year), (the contiguous patterns are interpolated from the station observations using the kriging method)

patterns using the Kriging method, to investigate the potential links between typical circulation types to annual precipitation patterns over the central and eastern TP (Fig. 5). It shows not surprisingly that the summertime patterns (e.g. types B4, C4 and C5) correspond to a relatively wetter precipitation regime than the wintertime patterns (e.g. types $\mathrm{A} 1, \mathrm{~A} 2$ and B5) and the transitional patterns (e.g. types A5,
B2 and C3), which further confirms the effectiveness of the SOM classification from the perspective of precipitation. Moreover, the annual precipitation patterns corresponding to all circulation types exhibit a similar spatial distribution with relatively more precipitation in the southeastern TP whereas relatively less precipitation in the northeastern TP, which indicates that the topographic features are 

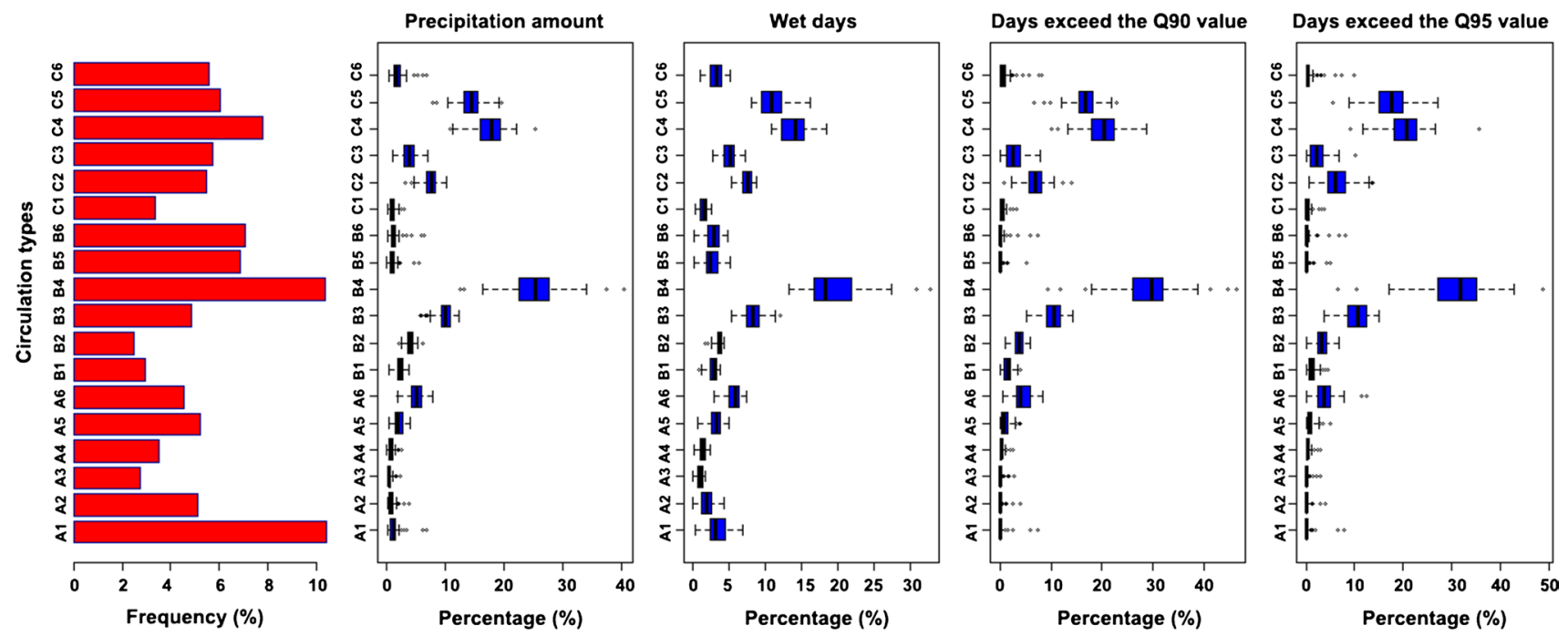

Fig. 6 Annual frequencies of 18 circulation types (the first panel) and their corresponding precipitation characteristics. The panels 2-5 show the percentages of precipitation characteristics (annual precip- itation amount, annual wet days and annual days with precipitation amount exceed the 90th quantle value and the 95th quantile value) corresponding to each circulation type to their annual totals also important factors influencing the spatial distribution of precipitation (Yin et al. 2004). Type A1 is the most frequent circulation type (10.43\%) and type B4 ranks second (10.35\%). However, the latter (Fig. 6) contributes more $(25.35 \%)$ to the annual total precipitation for all stations over the central and eastern $\mathrm{TP}$ rather than the former $(1.26 \%)$. Type B2, by contrast, is the least frequent types among others $(2.48 \%)$ with a small contribution to annual mean precipitation of all station $(3.84 \%)$.

Obvious seasonal differences are also shown in the classified circulation types and their corresponding composite precipitation in the eastern and central TP (Fig. 7). Specifically, almost all circulation types may appear in spring (except for two typical summer types B4 and C5) and autumn (except for types A2 and B5), which suggests that the circulation patterns in the northern hemisphere swing dramatically during the springtime and autumntime. The top four wet types C2, A6, C6 and C3 in spring account for $71.42 \%$ of the total seasonal precipitation while the wet types B3, A6, C4, C2, B2 and C5 in autumn account for $76.89 \%$ of the autumn precipitation. In comparison, the numbers of the classified circulation types are relatively less in summer (seven) and winter (eight). Moreover, there is no one circulation type appears both in summer and winter which reveals different physical mechanisms influencing the TP precipitation between the two seasons. The four leading wet circulation patterns in summer are types B4, C4, C5 and B3 which account for $97.12 \%$ of the summer precipitation. In the summer types, there is an cyclconic circulation anomaly over the Bay of Bengal,which will be helpful for the Indian summer monsoon to bring the water vapor in the Bay of Bengal to the southeastern plateau.
Moreover, the enhanced and northward shifted SH over the northwest Pacific is expected to help the East Asian summer monsoon to take abundant low-latitude moisture from the northwest Pacific to the eastern TP. The central and eastern TP becomes a water vapor sink due to the convergence of the two airflows and thus increases precipitation. In winter, types A1, B5, A2 and B6 are the dominant circulation patterns which contribute $93.20 \%$ of the total winter precipitation (primarily snow). An anticyclonic circulation anomaly appears over the Bay of Bengal in the winter types and the SH over the northwest Pacific weakens and shifts southward (over the Philippines), which hamper the water vapor transport from the sea to the southern and eastern plateau. The water vapor transportation of mid-latitudes westerlies is also insufficient. Moreover, the divergence formed over the central and eastern TP is also adverse to appearance of the precipitation. It is interesting to note that the four dominating wet types in a year are the same as for the summer, which again confirms the dominant summer precipitation in the region. It is also noted that the summer have unique major wet types, while the four major wet types in the spring and autumn have two types in common, i.e. type C2 and type A6. Therefore, the seasonal variation of the circulation types also means that different seasons in general have different circulations types that cause precipitation.

\subsection{Interannual variability for the frequencies of the circulation types and their links to major teleconnection patterns and monsoons}

The frequencies of the circulation types exhibited different interannual variability during the past 50 years (Fig. 8). For 

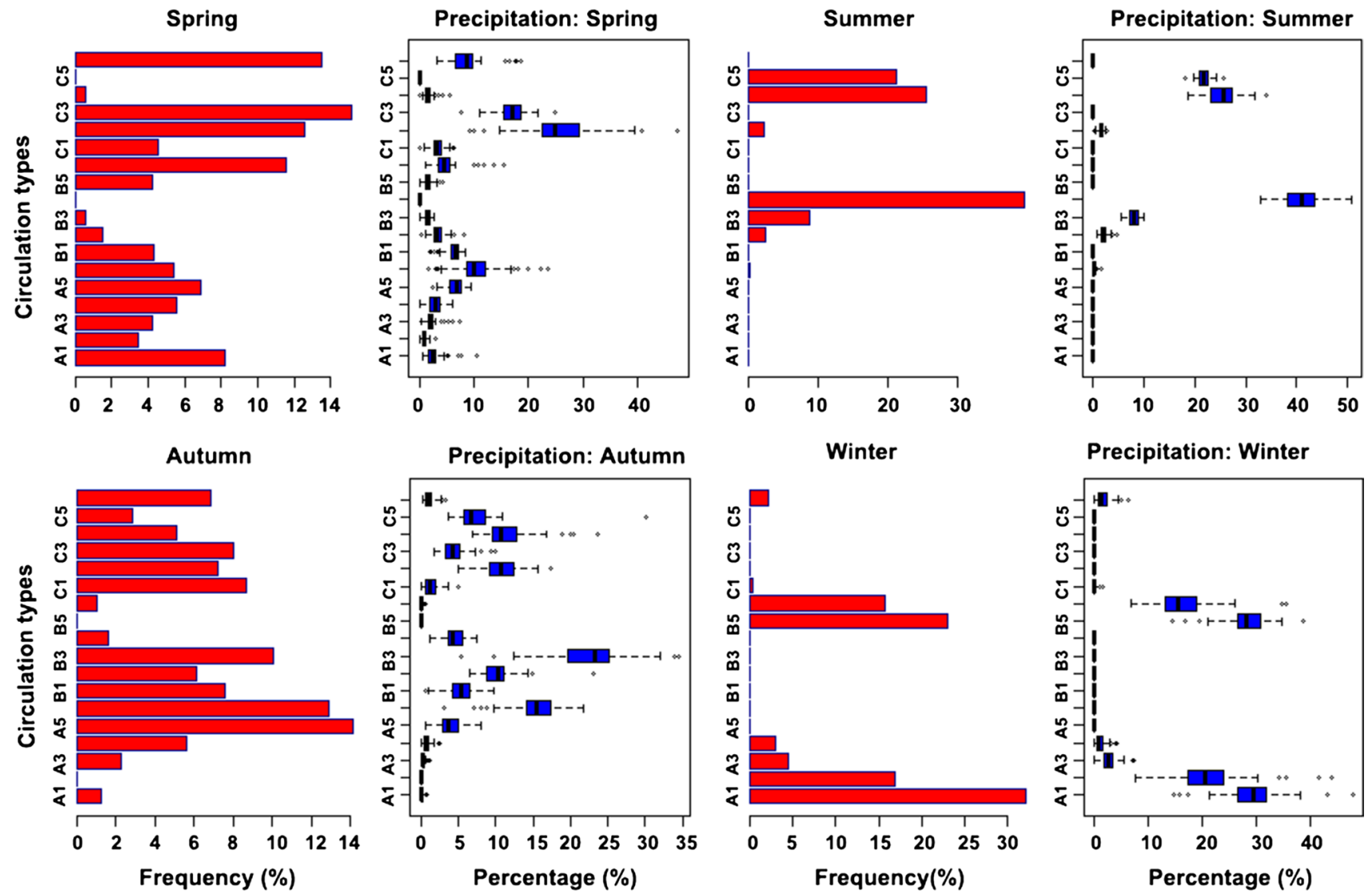

Precipitation: Winter

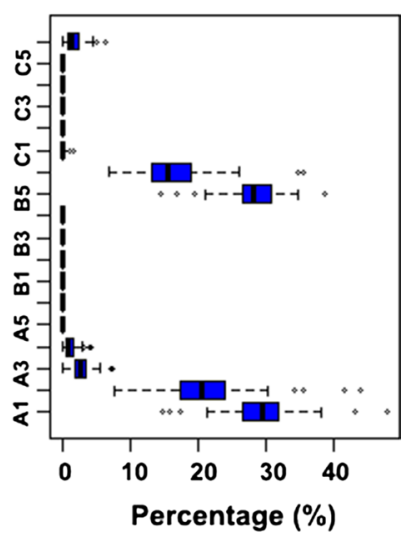

Fig. 7 Seasonal frequencies of 18 circulation types (the columns 1 and 3) and their corresponding precipitation amount. The columns 2 and 4 in this figures show the percentages of seasonal precipitation amount corresponding to each circulation type to their seasonal totals

example, types A1, A4, A5, A6, B3 and B4 showed obviously decrease while types B5, B6, C1, C2, C3, C4, C5 and C6 exhibited distinct increase from the late 1970s. Other types such as A2, A3, B1 and B2 did not reveal statistically significant variations. Moreover, all the frequency series for the distinctly varied circulation types showed significant abrupt changes in the late 1970s. They are interestingly consistent with some existing findings and reveal that the circulation types classified could to some extent reflect the variability of large-scale climate signals. For example, the observed abruptly shift of climate system over the eastern tropical Pacific and the northern Pacific Ocean during the period 1976-1977 (Graham 1994). Similarly, the frequency and intensity of El Niño events were also found to increase in 1976 due to the change of the vertical thermal structure of the eastern tropical Pacific (Guilderson and Schrag 1998).

The GH500 field used in this study covers almost the whole northern hemisphere, which ensures that the variability in the large scale circulation over the domain could be reflected through the variation of the circulation modes classified from the field. It is thus very interesting to further explore the extent to which the classified circulation types are related to the well-established and understood major circulation patterns. Table 3 shows the interannual correlations between the frequency of the 18 classified circulation types and 13 commonly used teleconnection patterns which may influence the TP climate. We can see that all the commonly used teleconnection indices have close links with at least one of the 18 circulation types, indicating the usefulness of the classification in reflecting some of the well-known processes. Another interesting feature is that 8 out of the 13 indices chosen to some extent reflect interannual variations of more than half of the circulations types, and the more circulation types reflected, the closer the correlation. The East Atlantic Pattern (EA) is the top climate pattern that has the strongest influence on most of the circulation types, followed closely by the El Niño Southern Oscillation (ENSO), the Pacific/North American Pattern (PNA) and the SCA. On the climate scale, the circulation patterns over the TP are commonly characterized by the westerlies in the north in winter and the Indian monsoon in the south in summer (Webster et al. 1998; Schiemann and Schaer 2009; Yao et al. 2012), which could also be indicated by the circulation types classified (Fig. 8; Table 3). For example, types C1 (A4) correlated positively 

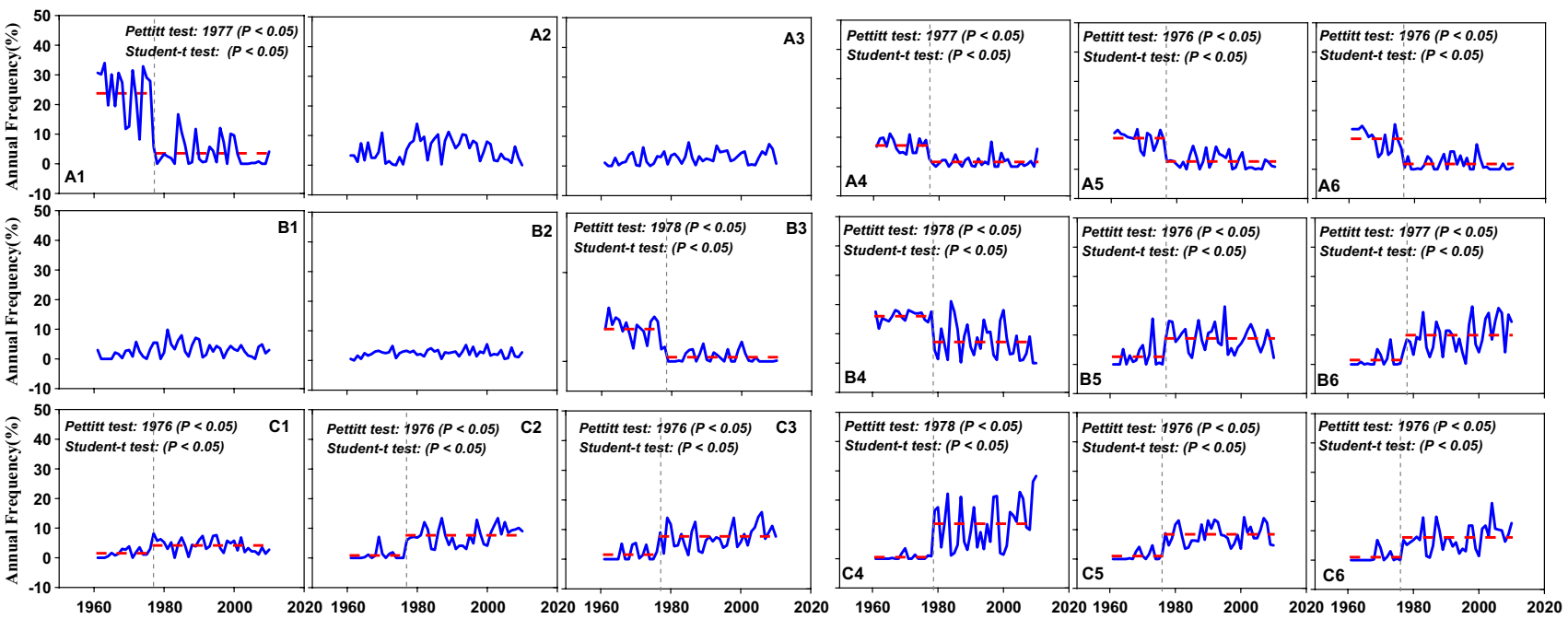

Fig. 8 Trends and variability for annual frequency of 18 synoptic circulation types. Results for the Pettitt test and the student t-test are shown and the abrupt change years (year after the Pettitt test) are also highlighted by the vertical dash line (gray color)

(negatively) with the zonal index which reflects the strength of westerlies in the Northern Hemisphere ( $\mathrm{Li}$ and Wang 2003a). Thus, the occurrence of type C1 (A4) increased (decreased) with the enhancement of mid-latitude westerly during the period 1961-2010, which have been revealed from the Deuterium excess record in a southern Tibetan ice core (Zhao et al. 2012). The Indian summer monsoon, indicated by the Indian Summer Monsoon Index (ISMI), shows significant association with circulation types A2 and B2. In agreement with the variability of ISMI during the past five decades, the frequencies of types A2 and B8 did not exhibit obvious changes as well. Moreover, the East Asian Summer Monsoon can also be reflected by, for example, types B4, C3 and C6 (Table 3). The reduction (increase) of the frequencies for type B4 (types C3 and C6) during the period 1961-2010 is consistent with the recent weakening of northern East Asian summer monsoon (Zhu et al. 2012). Moreover, the EA, the ENSO, the PNA, the mid-latitude westerly (ZI) and the SCA are also showed significant abrupt changes in the late 1970s (Fig. 9). All above patterns except for the SCA exhibit increase from the change point, for example, the EA transited from its negative phase to positive phase since 1976 (Iglesias et al. 2014).

\subsection{Linkages between the classified circulation types and local precipitation}

The change in the frequency of a given synoptic type would theoretically influence the change of its corresponding precipitation statistics. Further, the changes of a region's precipitation are mainly (not consider the convection and other local effects) attribute to the combined effect of all circulation types. Now we would like to explore the relationships between the interannual variations and changes of the precipitation and those of the 18 circulations types. Over the past 50 years, all the annual precipitation statistics in the eastern and central TP showed increasing trends, and especially, the extreme precipitation days (with thresholds Q90 and Q95, respectively) exhibited substantially manifold (bottom panel in Fig. 10) which are closely related with the variations/changes for the types A1, A6, B4 and B5 (Table 4). Types C1, C4 and C5 are more relevant to the extreme precipitation days with a relatively less threshold (Q90). The interannual variations and trends of the composite precipitations are broadly consistent with those of their correspondingly circulation types (Figs. 8, 10, Table 4). Of course this constancy is more relevant for the frequent circulation types that are associated with large precipitation amounts. For example, although the frequency and variability of type A1 are high, it has only a minor effect on the variation of the annual precipitation because it is a dry pattern. On the contrary, the type $\mathrm{C} 4$ contributes the most to the annual precipitation variability because it corresponds to a large amount of summer precipitation. Moreover, the corresponding composite precipitations of circulation types also show significant abrupt changes in the late 1970s, which further ensure that the abrupt changes detected in the circulation types are not artifact of the reanalysis due to the changes of the observing system (e.g. the advent of the satellite data). Simultaneously, the extreme precipitation days in the eastern and central TP also exhibited distinct changes in 1977. We can therefore speculate that the abrupt increase of extreme precipitation days in this region after 1977 may to some extent link to the climate shift over the eastern tropical Pacific and the northern Pacific Ocean (Miller et al. 1994) as well as the phase/intensity transitions 


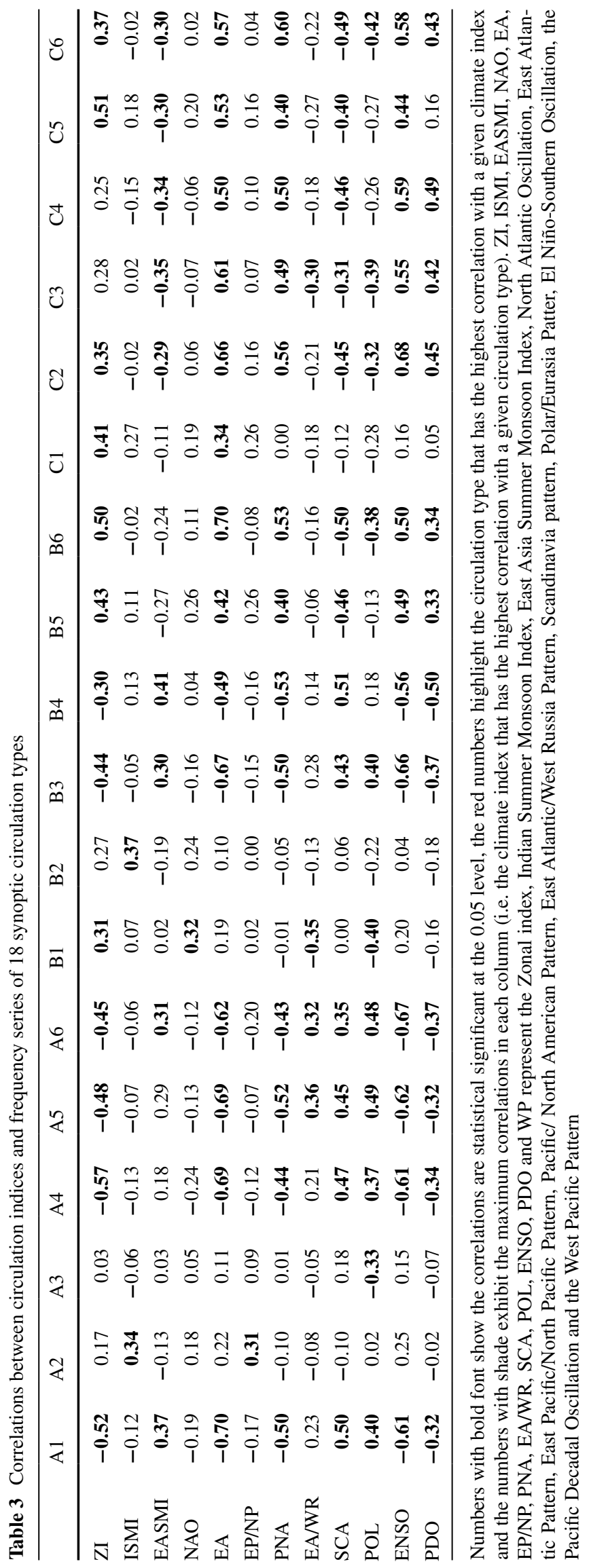




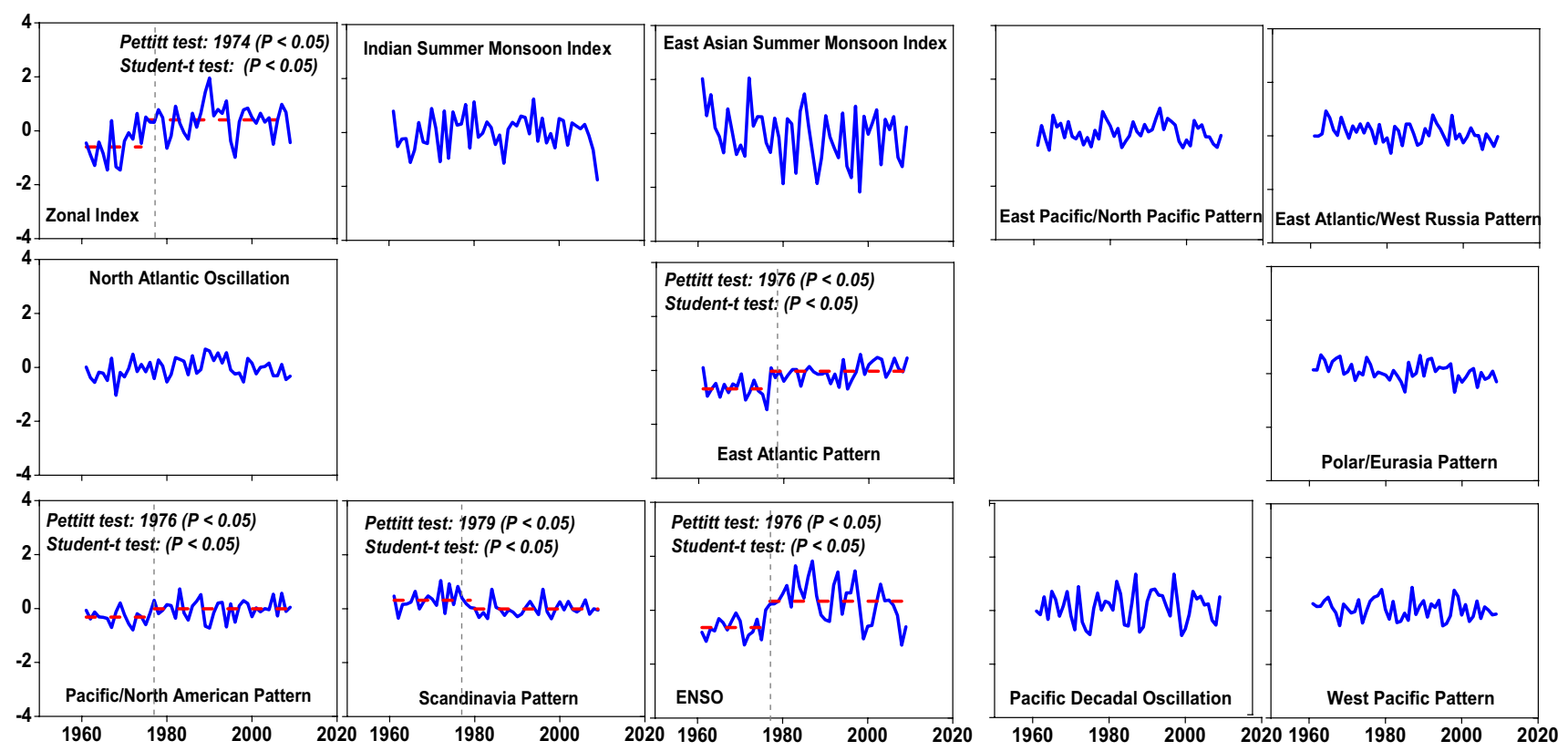

Fig. 9 Trends and variability for the annual indices of major teleconnection patterns and monsoons. Results for the Pettitt test and the student t-test are shown and the abrupt change years are also highlighted by the vertical dash line (gray color)
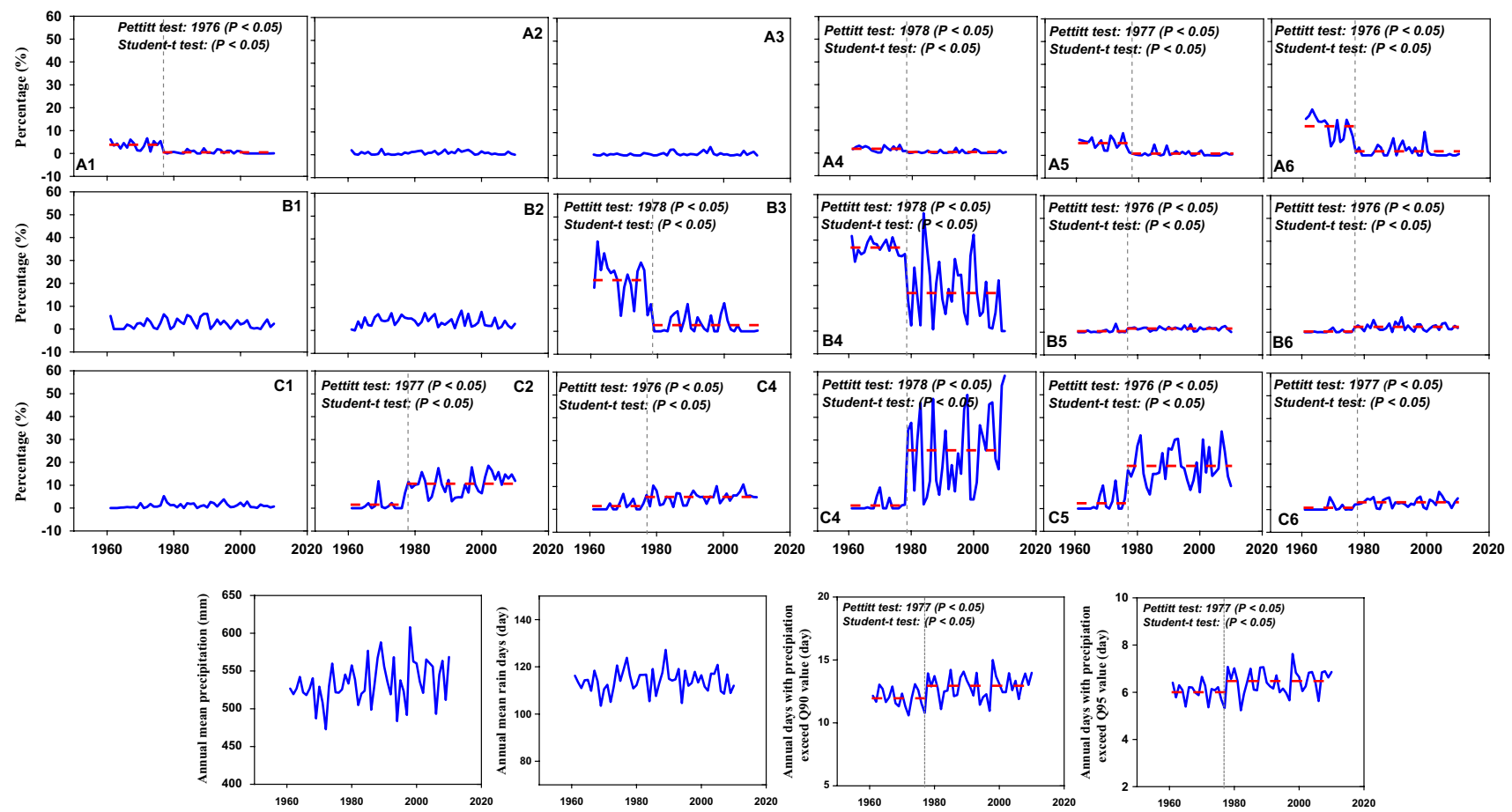

Fig. 10 Trends and variability for annual composite precipitation corresponding to 18 circulation types and for annual total precipitation statistics. Abbreviations are same as in Fig. 8

of EA/ENSO during the period 1976-1977 (Guilderson and Schrag 1998).

To quantify the relationships and the explaining capacity of the classified circulation types for the interannual variations of the mean precipitation in the study region, we use the SLR to link the seasonal precipitation and frequencies of the circulation types (Fig. 11). If the obtained circulation types can reasonably explain the regional 
Table 4 Correlations between the annual frequencies of circulation types and precipitation statistics (CAPA: annual precipitation amount corresponding each circulation types; ARPA: annual regional pre- cipitation amount; RARD: annual regional rain days; RAD90 annual regional days with precipitation exceed the Q90 value; RAD95 annual regional days with precipitation exceed the Q95 value)

\begin{tabular}{lrlllllllllllllllll}
\hline & A1 & A2 & A3 & A4 & A5 & A6 & B1 & B2 & B3 & B4 & B5 & C6 & C1 & C2 & C3 & C4 & C5 & C6 \\
\hline CAPA & $\mathbf{0 . 9 2}$ & $\mathbf{0 . 7 9}$ & $\mathbf{0 . 6 5}$ & $\mathbf{0 . 8 9}$ & $\mathbf{0 . 8 6}$ & $\mathbf{0 . 9 9}$ & $\mathbf{0 . 7 8}$ & $\mathbf{0 . 9 8}$ & $\mathbf{0 . 9 4}$ & $\mathbf{0 . 8 5}$ & $\mathbf{0 . 9 3}$ & $\mathbf{0 . 9 8}$ & $\mathbf{0 . 9 9}$ & $\mathbf{0 . 8 3}$ & $\mathbf{0 . 7 7}$ & $\mathbf{1 . 0 0}$ & $\mathbf{0 . 9 8}$ & $\mathbf{0 . 9 1}$ \\
ARPA & -0.22 & 0.09 & 0.02 & 0.26 & 0.02 & -0.18 & 0.23 & 0.11 & 0.10 & -0.17 & -0.22 & -0.13 & -0.18 & 0.08 & 0.12 & 0.15 & 0.27 & 0.19 \\
ARRD & -0.02 & 0.04 & 0.02 & 0.21 & -0.21 & 0.04 & 0.12 & 0.01 & -0.09 & -0.01 & -0.03 & 0.01 & -0.03 & 0.05 & -0.10 & -0.01 & 0.08 & 0.04 \\
ARD90 & $\mathbf{- 0 . 3 2}$ & 0.14 & 0.13 & 0.24 & 0.01 & $\mathbf{- 0 . 2 8}$ & 0.17 & 0.19 & 0.19 & $\mathbf{- 0 . 2 8}$ & $\mathbf{- 0 . 3 0}$ & -0.20 & $\mathbf{- 0 . 2 8}$ & 0.10 & 0.27 & $\mathbf{0 . 2 8}$ & $\mathbf{0 . 3 1}$ & 0.21 \\
ARD95 & $\mathbf{- 0 . 3 3}$ & 0.20 & 0.09 & 0.26 & 0.14 & $\mathbf{- 0 . 3 0}$ & 0.20 & 0.16 & 0.19 & $\mathbf{- 0 . 3 2}$ & $\mathbf{- 0 . 2 8}$ & -0.22 & -0.17 & 0.14 & 0.24 & 0.21 & 0.27 & 0.23 \\
\hline
\end{tabular}

Numbers with bold font show the correlations are statistical significant at the 0.05 level
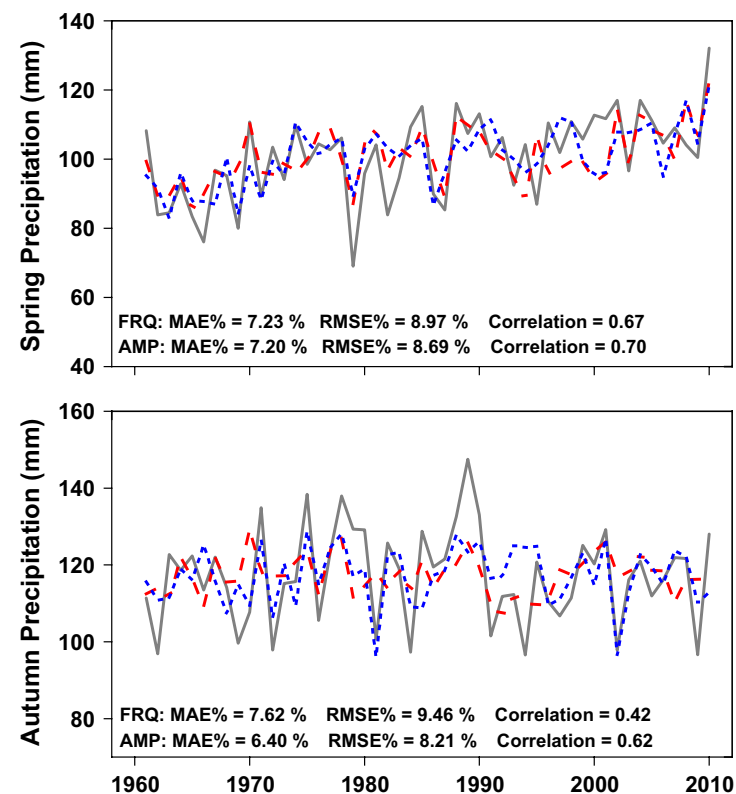

Fig. 11 The potential predictability of classified synoptic types (frequency and amplitude) for seasonal precipitation variability in the eastern and central TP. The MAE\%, RMSE\% and Correlation in label mean the mean absolute error $(\%)$, root mean square error $(\%)$ and

precipitation variability, they would be useful indicators for precipitation modeling/forecasting. The frequencies of circulation types exhibit some prediction skill for the spring and winter precipitation amounts with the Pearson correlations between the observed and the SLR-reconstructed precipitation being 0.67 and 0.55 , respectively. For the summer and autumn precipitation amounts, the established models have a relatively poor performance with the mean absolute error (MAE \%), root mean square error (RMSE $\%$ ) and the Pearson correlation coefficients $5.05 \%, 6.87 \%$, 0.32 as well as $7.6 \%, 9.46 \%$ and 0.43 . Compare to the frequency series, the amplitude series show relatively better predictability (Fig. 11). For example, the correlation coefficients between the observed and SLR-constructed seasonal precipitation using the amplitude series are $0.70,0.81,0.62$
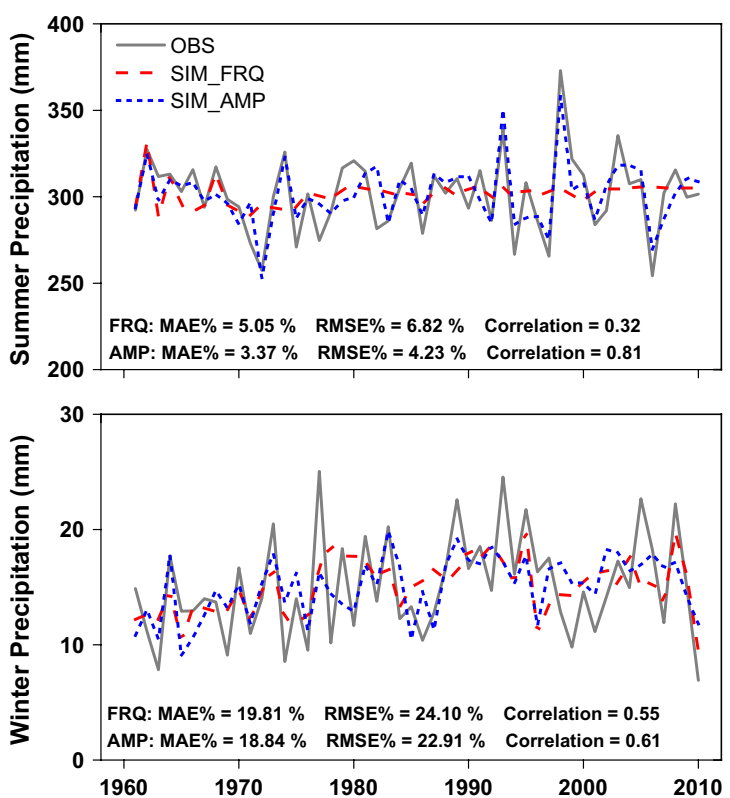

the Pearson correlation coefficient between the observed seasonal precipitation (OBS) and the simulated precipitation using the frequency (SIM_FRQ) and amplitude (SIM_AMP) of synoptic types

and 0.61 for the four seasons, respectively. It demonstrates that the classified circulation types closely link the regional precipitation over the central and eastern TP and indeed exhibit an overall promising explaining capacity based on merely the variability of a fairly small number of circulation patterns classified from only the geopotential height field at the $500 \mathrm{hPa}$ vertical height.

\section{Conclusions}

The large-scale circulation classification provides us an ideal tool to understand the circulation dynamics and their association with local climate variability. In this study, daily circulation types are objectively characterized 
through the use of SOM technique, and are further linked to the daily precipitation characteristics in the eastern and central TP during the period 1961-2010.

Results show that the SOM method adopted could reasonable classify the daily geopotential height field at the $500 \mathrm{hPa}$ vertical level over the area covering the TP. By using an objective determining method (the Pettitt test combines with the student t-test), 18 circulation types are qualified. Specifically, the large amount of precipitation in summer is closely associated with the circulation types B4, C4 and C5, in which the enhanced and northward shifted $\mathrm{SH}$ over the northwest Pacific and the obvious cyclconic circulation anomaly over the Bay of Bengal are helpful for the Indian summer monsoon and East Asian summer monsoon to take abundant low-latitude moisture to the eastern and southern TP. Conversely, the dry winter is dominated by the circulation types $\mathrm{A} 1, \mathrm{~B} 5$ and $\mathrm{A} 2$, in which a divergence formed over the central and eastern TP and the water vapor transportations of East Asian winter monsoon and mid-latitude westerly are very weak. Additionally, most of the classified circulation patterns may appear in other seasons with the predominant types $\mathrm{C} 2, \mathrm{C} 3$ and $\mathrm{A} 6$ for spring and types B3, A6 and C3 for autumn. The frequencies of the classified circulation types are closely related to the interannual variability of some large-scale teleconnection patterns (e.g. EA, ENSO, PNA and SCA), East Asian Monsoon, Indian Summer Monsoon and the mid-latitude westerly during the period 1961-2010. The composite precipitations show broadly consistent trends with the interannual variations of the frequencies for their corresponding circulation types, and some of which (e.g. types A1, A6, B4 and B5) are responsible for the increase of annual precipitation statistics (e.g. the extreme precipitation days) over the eastern and central TP. The climate shift signals in the late 1970s over the eastern tropical Pacific and North Pacific Ocean could be reflected by both the frequency of classified circulation types and their correspondingly composite precipitation, which could further help us to explain the abrupt change in 1977 for the extreme precipitation days in the central and eastern TP. Additionally, the frequency and amplitude series of the classified circulation types exhibit an overall promising predictability capacity of the seasonal precipitation, especially for spring and winter precipitations in the central and eastern TP. This study presents a preliminary work to link the regional precipitation to the predominant circulation types classified based on the original GH500 field. More circulation variables such as the specific humidity and the water vapor at various vertical heights (e.g. $200,700 \mathrm{hPa}$ ), could also be used in the classification through multivariate SOM training or creating the node-average plots for additional atmospheric fields associated with each SOM pattern (Lennard and Hegerl 2014), although the effectiveness and feasibility of multivariable SOM training still need further demonstration. Moreover, the anomaly field is also usually used in the circulation classification and indeed shows relatively better predictability capacity for the regional climate variables compares to the original field (Johnson et al. 2008; Rousi et al. 2015). However, in this study, we look at the daily values for the whole and the mean is a constant for all the days, which mean the anomaly field does not contain more information than the original value. So far, we have used the original values which are relevant and indeed useful to identify the seasonal variations of circulation types. Consequently, the circulation classification using the original GH500 field is acceptable for deepening our basic understandings in an unexplored region as the first step and the anomaly field would be adopted when we further investigate the quantitative relationships between the circulation types and local precipitation. All aspects mentioned above may be considered in our future studies for comprehensively understanding the climate variability in the largest plateau in the world and further for downscaling/projecting the TP precipitation using the frequency/ amplitude series of the circulation types, which are classified/calculated from the reanalysis/GCMs/RCMs, as the crucial predictors (Liu et al. 2013, 2015; Zhang and Yan 2015).

Acknowledgments This study was financially supported by the National Key Basic Research Program of China (2013CBA018), the "Strategic Priority Research Program" of the Chinese Academy of Sciences (XDB03030302) and the National Natural Science Foundation of China (Grant 41401037 and 41322001). Lei Wang was also supported by the Hundred Talent Programs of Chinese Academy of Sciences. We also wish to thank the editor and two anonymous reviewers for their invaluable comments and constructive suggestions used to improve the quality of the manuscript.

\section{References}

Barmston A, Livezey RE (1987) Classification, seasonality and persistence of low frequency atmospheric circulation patterns. Mon Wea Rev 82:1083-1126

Belleflamme A, Fettweis X, Erpicum M (2015) Do global warming-induced circulation pattern changes affect temperature and precipitation over Europe during summer? Int $\mathrm{J}$ Climatol 35(7):1484-1499

Bothe O, Fraedrich K, Zhu XH (2010) Large-scale circulations and Tibetan Plateau summer drought and wetness in a high-resolution climate model. Int J Climatol 31(6):823-846

Bothe O, Fraedrich K, Zhu XH (2012) Tibetan Plateau summer precipitation: covariability with circulation indices. Theor Appl Climatol 108:293-300

Cassano EN, Lynch AH, Cassano JJ, Koslow MR (2006) Classification of synoptic patterns in the western Arctic associated with extreme events at barrow, Alaska, USA. Clim Res 30:83-97

Cavazos T (2000) Using self-organizing maps to investigate extreme climate events: an application to wintertime precipitation in the Balkans. J Clim 13:1718-1732 
Chan JCL, Zhou W (2005) PDO, ENSO and early summer monsoon rainfall over South China. Geophys Res Lett 32:L08810. doi:10. 1029/2004GL022015

Chen DL (2000) A monthly circulation climatology for Sweden and its application to a winter temperature case study. Int J Climatol 20:1067-1076

Duan AM, Wu GX (2006) Change of cloud amount and the climate warming on the Tibetan Plateau. Geophys Res Lett 33:L22704. doi:10.1029/2006GL027946

Feng L, Zhou TJ (2012) Water vapor transport for summer precipitation over the Tibetan Plateau: multidata set analysis. J Geophys Res 117:D20114. doi:10.1029/2011JD017012

Gao Y, Wang HJ, Li SL (2013) Influences of the Atlantic Ocean on the summer precipitation of the southeastern Tibetan Plateau. J Geophys Res 118:3534-3544. doi:10.1002/jgrd.50290

Graham NE (1994) Decadal scale variability in the 1970's and 1980's: observations and model results. Clim Dyn 10:60-70

Guilderson TP, Schrag DP (1998) Abrupt shift in subsurface temperatures in the tropical Pacific associated with changes in El Niño. Science 281(5374):240-243

Gutiérrez JM, Cano R, Cofiño AS, Sordo C (2005) Analysis and downscaling multi-model seasonal forecasts in Peru using selforganizing maps. Tellus 57A:435-447

Hewitson BC, Crane RG (2002) Self-organizing maps: applications to synoptic climatology. Clim Res 22:13-36

Huth R, Beck C, Philipp A, Demuzere M, Ustrnual Z, Cahynová M, Kyselý J, Tveito OE (2008) Classifications of atmospheric circulation patterns: recent advances and applications. Trends Dir Clim Res Ann NY Acad Sci 1146:105-152

Iglesias I, Lorenzo MN, Taboada JJ (2014) Seasonal predictability of the East atlantic pattern from sea surface temperatures. PLoS One 9(1):e86439

Immerzeel WW, van Beek LPH, Bierkens MFP (2010) Climate change will affect the Asian water towers. Science 328:1382-1385

IPCC (2013) Climate Change 2013: the physical science basis. contribution of working group $\mathrm{i}$ to the fifth assessment report of the intergovernmental panel on climate change. In: Stocker TF, Qin D, Plattner G-K, Tignor M, Allen SK, Boschung J, Nauels A, Xia, Bex V, Midgley PM (eds). Cambridge University Press: Cambridge, United Kingdom and New York, NY, USA, p 1535

James PM (2007) An objective classification method for Hess and Brezowsky Grosswetterlagen over Europe. Theor Appl Climatol $88: 17-42$

Johnson NC (2013) How many ENSO flavors can we distinguish? J Clim 26:4816-4827

Johnson NC, Feldstein SB (2010) The continuum of North Pacific Sea level pressure patterns: intraseasonal, interannual, and interdecadal variability. J Clim 23:851-867

Johnson NC, Feldstein SB, Tremblay B (2008) The continuum of Northern Hemisphere teleconnection patterns and a description of the NAO shift with the use of self-organizing maps. J Clim 21:6354-6371

Kalnay E et al (1996) The NCEP/NCAR 40-year reanalysis project. Bull Am Meteorol Soc 77:437-471

Kohonen T (1995) Springer series in information sciences. In: SelfOrganizing Maps, vol 30. Springer, Berlin

Kohonen T (2001) Springer series in information sciences. In: SelfOrganizing Maps, 3rd edn, vol 30. Springer, Berlin

Lamb HH (1950) Types and spells of weather around the year in the British Isles: annual trends, seasonal structure of the year, singularities. Q J R Meteorol Soc 76:393-429

Lei YB, Yang K, Wang B, Sheng YW, Bird BW, Zhang GQ, Tian LD (2014) Response of inland lake dynamics over the Tibetan Plateau to climate change. Clim Change 125:281-290
Lennard C, Hegerl G (2014) Relating changes in synoptic circulation to the surface rainfall response using self-organising maps. Clim Dyn 44:861-879

Li J, Wang JX (2003) A modified zonal index and its physical sense. Geophys Res Lett 30:1632

Li J, Zeng QC (2003) A new monsoon index and the geographical distribution of the global monsoons. Adv Atmos Sci 20:299-302

Liu YG, Weisberg RH (2011) A review of self-organizing map applications in meteorology and oceanography. In: Mwasiagi JI (ed) Self organizing maps - applications and novel algorithm design, InTech. ISBN:978-953-307-546-4. http://www.intechopen.com/ books/selforganizing-maps-applications-and-novel-algorithmdesign/a-review-of-self-organizing-map-applications-inmeteorology-and-oceanography

Liu XD, Yin ZY (2001) Spatial and temporal variation of summer precipitation over the eastern Tibetan Plateau and the North Atlantic oscillation. J Clim 14:2896-2909

Liu YG, Weisberg RH, Christopher NLM (2006) Performance evaluation of the self-organizing map for feature extraction. J Geophys Res 111:C05018. doi:10.1029/2005JC003117

Liu WB, Fu GB, Liu CM, Charles SP (2013) A comparison of three multi-site statistical downscaling models for daily rainfall in the North China Plain. Theor Appl Climatol 111:585-600

Liu WB, Zhang AJ, Wang L, Fu GB, Chen DL, Liu CM, Cai TJ (2015) Projecting streamflow in the Tangwang river basin (China) using a rainfall generator and two hydrological models. Clim Res 62:79-97

Miller AJ, Cayan DR, Barnett TP, Graham NE, Oberhuber JM (1994) The 1976-1977 climate shift of the Pacific Ocean. Oceanography 7(1):21-26

Pettitt AN (1979) A non-parametric approach to the change point problem. Appl Stat 28(2):126-135

Philipp A, Beck C, Huth R, Jacobeit J (2014) Development and comparison of circulation type classifications using the COST 733 dataset and software. Int J Climatol. doi:10.1002/joc.3920

Rousi E, Anagnostopoulou C, Tolika K, Maheras P (2015) Representing teleconnection patterns over Europe: a comparison of SOM and PCA methods. Atmos Res 152:123-137

Sammon JW (1969) A nonlinear mapping for data structure analysis. IEEE Trans Comput C-18:401-409

Schiemann RD, Schaer C (2009) Seasonality and interannual variability of the westerly jet in the Tibetan Plateau region. J Clim 22:2940-2957

Sheridan SC, Lee CC (2011) The self-organizing map in synoptic climatological research. Prog Phys Geogr 35:109. doi:10.1177/0309133310397582

Sugimoto S, Ueno K, Sha W (2008) Transportation of water vapor into the Tibetan Plateau in the case of a passing synoptic-scale trough. J Meteorol Soc Jpn 86:935-949

Trenberth KE (1997) The definition of El Niño. Bull Am Meteorol Soc 78:2771-2777

Tveito OE (2010) An assessment of circulation type classifications for precipitation distribution in Norway. Phys Chem Earth 35:395-402

Verdon-Kidd DC, Kiem AS (2009) On the relationship between largescale climate modes and regional synoptic patterns that drive Victorian rainfall. Hydrol Earth Syst Sci 13:467-479

Vesanto J, Himberg J, Alhoniemi E and Parhankangas J (2000) SOM toolbox for Matlab 5, report, Helsinki Univ. of Technol., Helsinki, Finland

Wang B, Wu R, Lau KM (2001) Interannual variability of Asian summer monsoon: contrast between the Indian and western North Pacific-East Asian monsoons. J Clim 14:4073-4090

Webster PJ, Magaña VO, Palmer TN, Shukla J, Tomas RA, Yanai M, Yasunari T (1998) Monsoons: processes, predictability, and the 
prospects for prediction. J Geophys Res 103(C7):14451-14510. doi:10.1029/97JC02719

Yang K, Ye B, Zhou D, Wu B, Foken T, Qin J, Zhou Z (2011) Responses of hydrological cycle to recent climate changes in the Tibetan Plateau. Clim Change 109:517-534

Yang K, Wu H, Qin J, Lin CG, Tang WJ, Chen YY (2014) Recent climate changes over the Tibetan Plateau and their impacts on energy and water cycle: a review. Glob Planet Change 112:79-91

Yao TD, Thompson L, Yang W, Yu WS, Gao Y, Guo XJ, Yang XX, Duan KQ, Zhao HB, Xu BQ, Pu JC, Lu AX, Xiang Y, Kattel DB, Joswiak D (2012) Different glacier status with atmospheric circulations in Tibetan Plateau and surroundings. Nat Clim Change $2: 1-5$

Yarnal B, Comrie AC, Frakes B, Brown DP (2001) Developments and prospects in synoptic climatology. Int J Clim 21:1923-1950

Yin ZY, Liu XD, Zhang XQ, Chung CF (2004) Using a geographic information system to improve special sensor microwave imager precipitation estimates over the Tibetan Plateau. J Geophys Res 109:D03110. doi:10.1029/2003JD003748

You QL, Kang SC, Aguilar E, Yan YP (2008) Changes in daily climate extremes in the eastern and central Tibetan Plateau during 1961-2006. J Geophys Res 113:D07101. doi:10.1029/200 7JD009389

Zhang XL, Yan XD (2015) A new statistical precipitation downscaling method with Baysian modelaveraging: a case study in China. Clim Dyn. doi:10.1007/s00382-015-2491-7

Zhao HB, Xu BQ, Yao TD, Wu GJ, Lin SB, Gao J, Wang M (2012) Deuterium excess record in a southern Tibetan ice core and its potential climatic implications. Clim Dyn 38:1791-1803

Zhu CW, Wang B, Qian WH, Zhang B (2012) Recent weakening of northern East Asian summer monsoon: a possible response to global warming. Geophys Res Lett 39:L09701. doi:10.1029/20 12GL051155 